\title{
Los pactos locales, entre el Derecho y la retórica política. Especial referencia al caso de Andalucía
}

\author{
José Joaquín Fernández Alles \\ Doctor en Derecho. Profesor Derecho Constitucional. Universidad de Cádiz
}

Sumario: I. EL PACTO LOCAL: UNA PROPUESTA PENDIENTE DE REALIZACIÓN. II. EL PACTO LOCAL DE ÁMBITO ESTATAL (1997-2000): UNA OPORTUNIDAD PERDIDA. III. EL PACTO LOCAL ANDALUZ. IV. CÓMO PASAR DE LA RETÓRICA POLÍTICA AL DERECHO EN EL DEBATE SOBRE LOS PACTOS LOCALES: UNAS PRECISIONES CONCEPTUALES. V. EL PACTO LOCAL COMO MÉTODO PARA LAS RELACIONES INTERGUBERNAMENTALES ENTRE LA COMUNIDAD AUTÓNOMA Y LOS ENTES LOCALES. VI. REFLEXIONES CONCLUSIVAS.

\section{EL PACTO LOCAL: UNA PROPUESTA PENDIENTE DE REALIZACIÓN}

La necesidad de realizar un balance sobre el Pacto Local, esa idea-fuerza que desde 1992 viene ocupando un espacio relevante en el debate español sobre el poder local y el Estado de las Autonomías, deriva de una realidad constatada en las Elecciones Locales de 25 de mayo de 2003: las fuerzas políticas españolas llevan ya más de una década fundamentando buena parte de su ideario sobre temas municipales en un proceso descentralizador que nunca termina por tomar forma. En efecto, pese a las variadas y atractivas propuestas surgidas en el ámbito nacional y en el autonómico, y el unánime consenso concitado por parte de todos los partidos políticos, lo cierto es que aún no se ha aprobado ningún Pacto Local en España. Es más, su falta de concreción ni sorprende ni preocupa a la mayoría de los publicistas, y a estas alturas muchos gobiernos autonómicos y grupos de la oposición lo adoptan como un simple reclamo político, conscientes de sus pocas posibilidades de prosperar. ¿Cuál es la causa de que los Pactos Locales no hayan superado la fase de propuesta?

En los últimos veinte años, el profundo cambio operado en la organización territorial por el bloque de la constitucionalidad y por su complejo sistema competencial no ha afectado por igual a todas las Administraciones Públicas, siendo especialmente beneficiadas las Comunidades Autónomas, quienes en términos generales han demostrado, como contraprestación, una indisimulada resistencia a la descentralización y a la simplificación administrativa. Si en la década de los ochenta del siglo xx, la 
resistencia la opuso la Administración General del Estado, desde ya hace diez años, esta reacción al cambio proviene de las Administraciones Públicas autonómicas, creadas con mimetismo de la instancia central, de quien han imitado su antaño afán por el centralismo (en este caso centralismo autonómico), la burocracia, el sobredimensionamiento e incluso la cultura clientelar. En poco tiempo, las Comunidades Autónomas han acumulado un poder político y financiero que no están dispuestas a renunciar en un proceso descentralizador en municipios y provincias. El resultado práctico del debate sobre los Pactos Locales lo ha dejado muy claro, y es por ello que su función haya quedado limitada a ser instrumento de propaganda política, pese a su recurrente invocación en exposiciones de motivos de leyes autonómicas de régimen local, programas de gobierno, proposiciones de ley y otros documentos parlamentarios ${ }^{1}$.

Sin embargo, la descentralización autonómica en los entes locales, núcleo principal del Pacto Local, no es ajena a la norma suprema, antes bien, se fundamenta en los preceptos constitucionales (el artículo $103.1 \mathrm{y}$ el artículo 31.2 CE) reguladores de los principios de eficacia y eficiencia como criterios que vinculan a los poderes públicos. Dispone el artículo 31.2 CE, sobre el gasto público, que se realizará una asignación equitativa de los recursos públicos y su programación y ejecución responderán a los criterios de eficiencia y economía. Precisamente, el principio de eficiencia, consistente en un principio de carácter económico cuya determinación resulta de la cuantía de las unidades económicas consumidas en la función administrativa, ha sido mejor cumplido por el Estado que por las Comunidades Autónomas. En Andalucía, basta leer los Informes del Tribunal de Cuentas y de la Cámara de Cuentas de Andalucía para comprobar la mejor propensión del Estado al cumplimiento de la eficacia ${ }^{2}$.

\footnotetext{
1 Véanse como ejemplos la Ley 7/1999, de 9 de abril, de Administración Local de Aragón, la Ley 9/1999, de 13 de mayo, de Ordenación de territorio de Canarias, la Ley 10/1998, de 2 de julio, de Ordenación del territorio y urbanismo de La Rioja, la Ley 1/1998, de 4 de junio, de Régimen Local de Castilla y León, la Ley 5/1997, de 22 de julio, de Administración local de Galicia, la Ley balear 8/2000, de 27 de octubre, de Consejos Insulares. BOE 279, de 21 de noviembre; la Ley Foral de modificación de la Ley 6/1990, de 2 de julio, de la Administración Local de Navarra. BO Parlamento de Navarra 62, de 5 de junio de 2002.

2 Cfr. J. Rodríguez-Arana, «Presente y futuro del Estado de las Autonomías: Hacia la Administración Única», $A A, 1,1996-1997$, p. 9; Proyecto de Presupuestos Generales del Estado para el año 2000. Introducción y Estructuras Presupuestarias, Capítulo VIII. Resúmenes del Presupuesto, MEH, Madrid, 199, pp. 67 ss. Informe Económico-Financiero de las Administraciones Territoriales en 1997, MAP, Madrid, 1998, pp. 101 ss y 215 ss. y La descentralización del gasto público en España. Período 1986-1997, Ministerio de Economía y Hacienda, Madrid, 1999, pp. 25-28. Sobre
} 
También lo constatamos a nivel estatal, con la invocación recurrente de los principios y preceptos constitucionales en el ámbito financiero y de la Administración periférica. Entre los años 1997 y 2002, los órganos legislativos y gubernamentales del Estado decidieron acometer la reforma del sistema financiero autonómico y del modelo de Administración periférica del Estado, así como las medidas legislativas reguladoras del frustrado Pacto Local, actualmente calificado con la expresión de «segunda descentralización»:

a) El problema financiero.- En parte por exigencia del proceso de convergencia europea (pacto de estabilidad), el sistema financiero autonómico fue revisado por la Ley 14/1996, de 30 de diciembre, de cesión de tributos del Estado a las Comunidades Autónomas y de medidas fiscales complementarias, a través de un modelo disperso, criticado incluso por algunos de quienes la propugnaron, y nacido bajo la sombra de la provisionalidad, que fue ampliado una vez concluido el quinquenio de su vigencia (1997-2001), por la Ley 21/2001, de 27 de diciembre, reguladora de las medidas fiscales y administrativas del nuevo sistema de financiación de las Comunidades Autónomas de régimen común y ciudades con estatuto de autonomía; legislación a su vez modificada por las leyes 46/2002, 51/2002 y 53/2002. De esta manera, el sistema de corresponsabilidad fiscal, iniciado en 1997 y ampliado a Andalucía por la Ley 19/2002, de 1 de julio, de cesión de tributos del Estado a la Comunidad Autónoma de Andalucía y de fijación del alcance y condiciones de dicha cesión, ha consolidado la conversión de las Comunidades Autónomas en corresponsables de la política de ingresos y también de gastos, a quienes se les concede capacidad normativa $^{3}$.

los entes locales, aunque no sea un fenómeno privativo de Andalucía, véase Informe Anual sobre el Sector Público Local Andaluz 2000. Sevilla, 2002, en http://www.ccuentas.es/informes/corporacion.htm.

3 El Estado cedió determinados tributos a la Junta por Ley 19/2002, de 1 de julio, del Régimen de cesión de tributos del Estado a la Comunidad Autónoma de Andalucía y de fijación del alcance y condiciones de dicha cesión. Véanse también LO 3/1996, de 27 de diciembre. BOE 313, de 28-12; J. PÉREz Royo, El nuevo modelo de financiación autonómica: análisis exclusivamente constitucional, Madrid, McGraw Hill, 1997, pp. 21-27, y J.L. GArcía RuIz; E. Girón, «Las incidencias del modelo de Estado en el sistema de financiación autonómica», Revista Española de Derecho Constitucional, $\mathrm{n}^{\circ}$ 51, 1997, pp. 155-158. El sistema de corresponsabilidad fiscal, concebido como método participativo de las Comunidades Autónomas en la política fiscal y tributaria del Estado, pese a su corta vigencia de cinco años, encontró una fuerte respuesta por insatisfacción de Cataluña, cuyas pretensiones han sido asumidas por Madrid y Valencia, y el rechazo, más por razones políticas que técnicas, de las Comunidades Autónomas de Andalucía, Extremadura y Castilla-La Mancha, que presentaron recursos de insconstitucionalidad contra la reforma del modelo de financiación autonómica. Sobre las relaciones entre el sistema autonómico y la última reforma, véase J. RUIZ-HUERTA y J. LÓPEZ LABORDA, «Catorce preguntas sobre el nuevo sistema de financiación auto- 
REAL-2002, núm. 290. FERNÁNDEZ ALLES, JOSÉ JOAQUÍN. LOS PACTOS LOCALES, ENTRE EL...

REAL 290 (SEPTIEMBRE-DICIEMBRE, 2002)

Resta por cumplir, con todo, el mandato del artículo $142 \mathrm{CE}$, que reconoce el derecho de los entes locales a participar en los tributos de las Comunidades Autónomas ${ }^{4}$, y de la Ley 39/1988 y de la Carta Europea de Autonomía Local, según las cuales los recursos financieros de las Entidades Locales deberán ser proporcionales a las competencias previstas por la Constitución; en la actualidad, representa menos del 50\%, frente al $70 \%$ de la media europea ${ }^{5}$. Es cierto que en el caso andaluz el Plan de Cooperación Municipal, creado en 1990, se configura como instrumento específico, dentro del Presupuesto de la Comunidad Autónoma Andaluza, para la colaboración económica con las Corporaciones Locales; también es verdad que la Consejería de Gobernación de la Junta de Andalucía ha afrontado con diversas medidas las necesidades reales de financiación de las Corporaciones Locales, e incluso desde 1999, a través de las leyes de pre-

nómica», Informe de las Comunidades Autónomas, 1996, Barcelona, Instituto de Derecho público, 1997, vol. I, pp. 581 ss.

${ }^{4}$ Cfr. Ferreiro Lapatza, Tratado de Derecho Financiero y Tributario Local, Madrid, Marcial Pons, 1993, pp. 13-57. Los debates doctrinales y políticos sobre la reforma se encuentran, especialmente en lo que respecta a la tributación local, en un estado avanzado. Véanse J.M. TEJERIzo LóPEZ, «La Ley Reguladora de las Haciendas Locales», Revista de Hacienda Autonómica y Local, vol. XIX, núm 55-56, pp. 97-118, Solé Vilanova, cit., pp. 249 a 288. Sobre las reformas realizables a corto plazo; J.M. LAGo MonTERo, «Reflexiones sobre una hipotética reforma del sistema de financiación de las Corporaciones Locales», Revista de Hacienda Local, v. XXIV, núm. 70, pp. 7989. La misma jurisprudencia constitucional no ha sido ajena a este fenómeno cuando se ha pronunciado sobre las haciendas locales a la luz de la igualdad, la autonomía y la suficiencia financiera de los entes locales. Al respecto véanse las STC 19/1987, 17-2 (BOE 4.3.1987), STC 83/1988, 13-10 (BOE 25-5-1988), STC 250/1988, 20-12 (BOE 13-1-1989), STC 331/1993, 12-11 (BOE 10-12-1993), STC 171/1996, 30-10 (BOE 3-12-1996). Dice RodríGUEZ-ARANA que para que sea posible esta operación es necesario que se produzca un reforzamiento financiero y material de dichos Entes en aras de poder realizar dignamente su función. Cfr. RodríGuez-Arana MuÑoz, «Reforma administrativa y Estado autonómico», AA, 23, 1996, p. 471.

${ }^{5}$ Cfr. J. Solé Vilanova, «La financiación de los entes locales». En Font y Llovet (dir.): Informe sobre el Gobierno Local, Primera Parte, Madrid, M.A.P., pp. 249 y ss; X. Álvarez Corbacho, «La contribución del Estado a la financiación de las Corporaciones Locales de Galicia», Revista de Hacienda Autonómica y Local, vol. XIX, 1989, núm. 55-56, pp. 119-135. Comisión Layfield, La reforma de las Haciendas Locales, Madrid, Instituto de Estudios Fiscales, 1982; y FerReiro LapaTzA, Tratado de Derecho Financiero y Tributario Local, Madrid, Marcial Pons, 1993, pp. 13-57. Los debates doctrinales y políticos sobre la reforma se encuentran, especialmente en lo que respecta a la tributación local, en un estado avanzado. Véanse J.M. TEJERIZo LÓPEZ, «La Ley Reguladora de las Haciendas Locales», Revista de Hacienda Autonómica y Local, vol. XIX, núm 55-56, pp. 97-118, Solé Vilanova, cit., pp. 249 a 288. Sobre las reformas realizables a corto plazo; J.M. Lago MonTERO, «Reflexiones sobre una hipotética reforma del sistema de financiación de las Corporaciones Locales», Revista de Hacienda Local, v. XXIV, núm. 70, pp. 79-89. La misma jurisprudencia constitucional no ha sido ajena a este fenómeno cuando se ha pronunciado sobre las haciendas locales a la luz de la igualdad, la autonomía y la suficiencia financiera de los entes locales. Al respecto véanse las STC 19/1987, 17-2 (BOE 4.3.1987), STC 83/1988, 13-10 (BOE 25.5.1988), STC 250/1988, 20-12 (BOE 13.1.1989), STC 331/1993, 12-11 (BOE 10.12.1993), STC 171/1996, $30-10$ (BOE 3.12.1996). 
supuesto de la CA de Andalucía ${ }^{6}$. Pero, sin duda, se trata de un sistema insuficiente, y la Junta de Andalucía, antes de operar la descentralización de facultades en cumplimiento del Pacto Local, debe complementar el sistema de financiación local regulado por la Ley 39/1988, de 28 de diciembre, Reguladora de las Haciendas Locales, reformando la legislación autonómica, empezando por la Ley 5/1983, de 19 de julio, de la Hacienda Pública de la Comunidad Autónoma de Andalucía.

Por ahora, además del artículo 30.4 de la Ley 9/2002, de 21 de diciembre, de Presupuestos de la Comunidad Autónoma de Andalucía, que, como cada año, ha autorizado al titular de la Consejería de Economía para dotar presupuestariamente cada delegación, se prevé que la delegación de facultades autonómicas deberá incluir la dotación de medios financieros para hacer frente a la actuación administrativa, en los términos que dispone el artículo 130.1 de la Ley 39/1988, de 28 de diciembre, Reguladora de las Haciendas Locales: «Cuando las Diputaciones Provinciales gestionen servicios propios de las Comunidades Autónomas, éstas, de acuerdo con su legislación, podrán fijar módulos de funcionamiento y financiación y niveles de rendimiento mínimo, otorgando al respecto las correspondientes dotaciones económicas. Las Diputaciones Provinciales podrán mejorar estos módulos y niveles utilizando sus propias disponibilidades presupuestarias». Según el artículo 6 de la Ley 12/1983, de 14 de octubre, del Proceso Autonómico: «Cuando las Diputaciones Provinciales gestionen servicios propios de las Comunidades Autónomas, éstas, de acuerdo con su legislación, podrán fijar módulos de funcionamiento y financiación y niveles de rendimiento mínimo, otorgando al respecto las correspondientes dotaciones económicas. Las Diputaciones Provinciales podrán mejorar estos módulos y niveles utilizando sus propias disponibilidades presupuestarias». Por su parte, el artículo 27.1 de la Ley básica 7/1985 exige que la delegación establezca los medios personales, materiales y económicos que se transfieran, y en el caso concreto de la delegación legislativa obligatoria de competencias o facultades en los municipios o provincias por ley, su párrafo 3 dispone que la delegación deberá

\footnotetext{
6 Desde el artículo 26.4 de la Ley 10/1998, de 28 de diciembre, del Presupuesto de la Comunidad Autónoma de Andalucía para 1999, al artículo 30.4 de la Ley 9/2002, de 21 de diciembre, de Presupuestos de la Comunidad Autónoma de Andalucía para 2003, cada año se ha autorizado al titular de la Consejería de Economía y Hacienda para realizar en el Presupuesto de la Comunidad Autónoma de Andalucía las adaptaciones que sean necesarias para transferir a favor de las Entidades Locales las partidas y cuantías que correspondan, en los procesos de traspaso y delegación de competencias, siempre que las mismas queden expresamente determinadas en los correspondientes acuerdos, correspondiendo, en otro caso, al Consejo de Gobierno la aprobación de las transferencias y minoraciones de créditos correspondientes. Desde entonces todas las leyes de presupuestos de la CA han contemplado idéntica previsión.
} 
REAL-2002, núm. 290. FERNÁNDEZ ALLES, JOSÉ JOAQUÍN. LOS PACTOS LOCALES, ENTRE EL...

REAL 290 (SEPTIEMBRE-DICIEMBRE, 2002)

ir acompañada de la dotación o el incremento de medios económicos para desempeñarlo.

b) La Administración periférica del Estado.- El proceso de simplificación y reforma administrativas constituyó el objeto de la Ley 6/1997, de 14 de abril, de Organización y Funcionamiento de la Administración General del Estado (LOFAGE), norma dirigida al cumplimiento del principio de economía en el gasto público regulado en el artículo $31.2 \mathrm{CE}$, al exigir la simplificación y reducción de la planta de la Administración General del Estado, especialmente del nivel periférico, donde quedaron suprimidas las estructuras provinciales de un determinado números de servicios que pasaron a integrarse en la Delegación del Gobierno, a la que se someten los Subdelegados del Gobierno ${ }^{7}$.

c) El frustrado Pacto Local de ámbito estatal ${ }^{8}$.- Entre 1997 y 1998 se anunció el denominado Pacto Local de ámbito estatal, acuerdo de descentralización de competencias autonómicas en los entes locales, regulado en principio por nueve leyes que quedaron reducidas a seis el día 21 de abril de 1999, fecha de su promulgación. El carácter complementario o auxiliar de estas reformas legislativas respecto al proceso de descentralización local quedó finalmente desmentido porque las leyes citadas se convirtieron en el núcleo principal de la propia reforma, esto es, en el Pacto Local mismo. Esas leyes fueron las siguientes: a) Ley Orgánica 7/1999, de 21-4, de modificación de la LO 2/1979, de 3-10, del Tribunal Constitucional; b) Ley Orgánica 8/1999, de 21-4 ${ }^{9}$, de modificación de la LO 5/85, de 19-6, del Régimen Electoral General; c) Ley Orgánica 9/1999, de 21 de abril, de modificación de la Ley Orgánica 9/1983, de 15 de julio, reguladora del Derecho de Reunión; d) Ley 11/1999, de 21-4, de modificación de la Ley 7/85, de 2-4, Reguladora de las Bases de Régimen Local y otras medidas

\footnotetext{
7 «(...) se suprimirán, refundirán o reestructurarán, previa consulta a los Delegados del Gobierno, los órganos cuya subsistencia resulte innecesaria a la vista de las competencias transferidas o delegadas a las Comunidades Autónomas, y cuando proceda, atendiendo al marco competencia, a las Corporaciones locales, y de los medios y servicios traspasados a las mismas» (artículo 31 in fine de la Ley 6/97, de 14-4, de Organización y Funcionamiento de la Administración General del Estado. J. Rodríguez-ArAnA, «La Administración Única y el proyecto de LOFAGE», cit., p. 34.

8 Cfr. MAP, El Pacto Local. Medidas para el desarrollo del Gobierno Local, Madrid, 1999, pp. 173-174, M. Ayuso, «El Pacto Local en la LRBRL: atribuciones del Alcalde y del Pleno municipal», RVAAutonómics, 26, 1999, pp. 237-262; L. PAREJo AlFonso, «Estado autonómico y Régimen Local», RAAP, 42, 2001, pp. 11 y ss.; J.L. RIVERO YSERN, «La cooperación interadministrativa local», RAAP, 46, 2002, pp. 57-94.

9 Cfr. LO 6/85, 19-6, cit., redacción LO 8/99, de 21-4, cit. MAP, El Pacto Local. Medidas para el desarrollo del Gobierno Local, cit., pp. 173-174, M. Ayuso, «El Pacto Local en la LRBRL: atribuciones del Alcalde y del Pleno municipal», RVAAutonómics, 26, 1999, pp. 237-262.
} 
para el desarrollo del Gobierno Local, en materia de tráfico, circulación de vehículos de motor y seguridad vial, y en materia de aguas; e) Ley Orgánica 10/1999, de 21-4, de modificación de la LO 8/1985, de 3-7, Reguladora del Derecho a la Educación; y f) Ley 10/1999, de 21-4, de modificación de la LO 1/1992, de 21-2, sobre protección de la Seguridad Ciudadana ${ }^{10}$.

d) Las reformas complementarias.- El Pacto Local, en cuanto proceso descentralizador en los entes locales, debe complementarse con la reforma del sistema electoral, del modelo de contratación pública local, del marco de coordinación urbanístico-medioambiental y, sobre todo, del régimen autonómico sobre la función pública, ya que la falta de un sistema funcionarial de los entes locales suficientemente sometido a los principios de coordinación, mérito y capacidad, permite afirmar que supondría un auténtico retroceso en la consecución de los principios constitucionales de mérito y capacidad, exigidos para el acceso a la función pública en el artículo 103.3 CE, que las competencias autonómicas fueran gestionadas en el futuro por entes locales que desde hace años llevan demostrando, a través de heterodoxos sistemas de selección de personal, la ignorancia de aquellos principios. Es una manifestación de lo que se ha venido a denominar la «huida del Derecho» por los entes locales.

\section{EL PACTO LOCAL DE ÁMBITO ESTATAL (1997-2000): UNA OPORTUNIDAD PERDIDA}

La resistencia que han opuesto los gobiernos autonómicos a la reforma descentralizadora en los entes locales, paralela a la emulación organizativa de las instancias centrales, ha consolidado un estado de duplicidades competenciales y disfunciones, propiciado por el complejo sistema competencial, que, además de contravenir los preceptos y principios constitucionales antes citados (artículo 31.2 y 103.1), en la práctica han causado un gran despilfarro financiero. Muchas competencias han estado administradas, y una parte considerable de ellas siguen siendo gestionadas, concurrentemente y de forma solapada y descoordinada por varias Adminis-

\footnotetext{
10 Cfr. AA.VV., El acceso de los entes locales al Tribunal Constitucional y la protección de la autonomía local, 1997; P. PÉrez TREMPs, La defensa de la autonomía local ante el Tribunal Constitucional, 1. ${ }^{\text {a }}$ ed. 1998, pp. 13; J. García Roca, Defensa de la autonomía local ante el Tribunal Constitucional, 1. ${ }^{a}$ ed., 1997, pp. 34-36; A. Gallego Anabitarte, Derechos fundamentales y garantías institucionales, 1. a ed., 1994, pp. 62 ss.; J. LóPEZ-Medel BÁscones, Entidades locales y descentralización en un Estado autonómico, 1994, pp. 38-42; L. PAREJo Alfonso, Garantía institucional y Autonomías locales, Madrid, 1981, pp. 42 ss.
} 
REAL-2002, núm. 290. FERNÁNDEZ ALLES, JOSÉ JOAQUÍN. LOS PACTOS LOCALES, ENTRE EL...

REAL 290 (SEPTIEMBRE-DICIEMBRE, 2002)

traciones, que destinan así doble presupuesto, oficinas y puestos de trabajo a la misma función.

Con el fin de corregir estas duplicidades y acompasar el funcionamiento competencial de las distintas Administraciones Públicas, durante los últimos veinte años se ha defendido en repetidas veces la necesidad de una reforma administrativa, que es secular promesa de todo gobernante. Las diversas propuestas, así las que se contienen en el Informe de la Comisión de Expertos de 1981, en la doctrina de la Administración única, o en los propios fundamentos jurídicos de la jurisprudencia constitucional, se han dirigido a lograr una mayor eficacia administrativa y cercanía al ciudadano, vertebrando una tendencia decididamente reformadora que, salvando las distancias, también ha sido experimentada en la doctrina comparada, donde encontramos, con similares trazos y principios inspiradores, los informes Tröger (Alemania), Kilbrandon (Reino Unido) Giannini o Ley Bassanini (Italia) o, en menor medida, el Informe Al Gore (Estados Unidos). Precisamente, en dos de las propuestas citadas, el Informe de la Comisión de Expertos (1981) y la Administración única (1992), se inspira el Pacto Local, llamado a la eliminación de las duplicidades y solapamientos competenciales a través de la atribución legislativa y de instrumentos de cooperación consorcial o directamente ejecutiva como la delegación o la encomienda de gestión de competencias autonómicas, principalmente a los Ayuntamientos, aunque también a las Diputaciones Provinciales, Mancomunidad de Municipios y Áreas Metropolitanas. Un proceso de fortalecimiento del poder local, siempre desarrollado en convenio intergubernamental, que constituye en España la última frontera en el proceso de descentralización derivado de la Constitución de 1978.

En el debate sobre la reordenación de las competencias administrativas autonómicas, los entes locales cuentan con la presunción de ser las instituciones más próximas a los ciudadanos, también con el fundamento jurídico que a su esfera de competencias le proporciona el principio de subsidiariedad y la Carta Europea de Autonomía Local de 15 de octubre de 1985 (arts. 3 y 4) ${ }^{11}$, y asimismo con el hecho cierto de que el ordenamiento jurídico, en diversas normas, ha encomendado a los entes locales

${ }^{11}$ En la versión inglesa se traduce como a substantial share y, en el texto en alemán, einen wesentlichen. Dice Font i Llovet que la Carta Europea de Autonomía Local, que proclama el principio de subsidiariedad y que fue aprobada en el seno del Consejo de Europa, puede dar mayor efectividad al principio de descentralización y máxima proximidad de la gestión administrativa a los ciudadanos, que se regula en el artículo 2.1 de la Ley 7/1985, 2 de abril. Cfr. T. FonT i LLovet, «El Gobierno Local: entre el Estado autonómico y la Unión Europea. Hacia el Pacto Local», Autonomies, 20, pp. 114-116; y J. BARNES, «Subsidiariedad y autonomía local en la Constitución», T. FonT I Llovet, Anuario del Gobierno Local, Madrid, 1997, pp. 53-62, y 95-97. 
la satisfacción de los servicios más elementales de la colectividad y los más cercanos al ciudadano ${ }^{12}$.

Ahora bien, en ese mismo debate, el legislador, tanto el estatal como el autonómico, se enfrenta a no pocas dificultades a cuya resolución queda condicionado el Pacto Local como conjunto de técnicas que han de relacionar los gobiernos locales con el gobierno autonómico. En primer lugar, permanece la necesidad de regular las competencias locales, especialmente las municipales, con una norma que se adapte al heterogéneo mapa español, con el 42 por ciento de la población concentrada en 54 municipios, y el 86 por ciento del total de municipios con una población inferior a los 5.000 habitantes. En segundo lugar, nos enfrentamos a la citada resistencia que opone la Administración autonómica a dejarse despojar de un poder recientemente adquirido y desarrollado por un nada despreciable cúmulo de influencias y redes de intereses; tendencia a la que alude ArENILLA, como efecto competencia-territorio, en virtud del cual una Administración que esté implantada en el territorio y con competencias en dicho territorio aspirará por todos los medios a ser el único poder en el mismo $^{13}$. Y, en tercer lugar, subsiste la circunstancia de que tras dos siglos

12 El profesor Parejo Alfonso defiende un contenido esencial de la Administración pública, que identifica con una imagen característica o de un típico institucional, muy relacionada con la concepción social dominante. Cfr. L. Parejo Alfonso, Eficacia y Administración. Tres estudios, cit., pp. 65-67. Sobre la delegación/encomienda de gestión en este ámbito, F. Sosa Wagner, Manual de Derecho Local, cit., pp. 71-77; S. MuÑoz Machado, Derecho Público de las Comunidades Autónomas, vol. II, Madrid, 1984, pp. 226-227; L. Morell OCAÑA, El régimen local, cit., pp. 574-577; L. ORTEGA, El régimen constitucional de las competencias locales, Madrid, 1988, pp. 146-151.

13 Sobre la caracterización de la garantía institucional, si bien referida a la autonomía local, en J. L. CARro FernándeZ-VALMAYor, «El debate sobre la autonomía municipal», RAP, 54, 1998, pp. 5996. También C. Sснмітт, Teoría de la Constitución, Alianza Universidad, Madrid, 1992, pp. 176177; K. STERn, Derecho del Estado de la República Federal Alemana, CEC, Madrid, 1987, pp. 702 y ss. A. Gallego Anabitarte, Derechos fundamentales y garantías institucionales: Análisis doctrinal y jurisprudencial, Civitas, Madrid, 1994, pp. 124 ss.; L. LóPEZ GuERRA, Introducción al Derecho Constitucional, Tirant lo Blanch, 1994, pp. 115 ss. Sobre la consideración de la autonomía local como límite frente al legislador, J. JiMÉNEZ CAMPO, «Notas sobre la protección de la autonomía local frente al legislador en el derecho español», REDC, 53, 1998, p. 42. Por su parte, PAREJo Alfonso hace referencia a la determinación de un contenido esencial de la Administración pública, que debe ser interpretado restrictivamente y que identifica con una imagen característica o de un típico institucional, muy relacionado con la concepción social dominante. Cfr. L. PAREJo ALFonso, Garantía institucional y autonomías locales, IEAL, Madrid, 1981, pp. 13 ss. y 48 ss.; y Eficacia y Administración. Tres estudios. Madrid, INAP, 1995, pp. 65-67. Sobre nuevas propuestas fundamentadoras de la autonomía local que ponen en cuestión la doctrina del Tribunal Constitucional sobre la garantía institucional, J.M. BANDRÉs SÁNCHEZ-CruZAT, El principio de subsidiariedad y la Administración Local, Marcial Pons, Madrid, 1999, pp. 49 ss.; aunque a todo ello dedicamos un apartado específico más abajo, véase sobre la más reciente defensa de una garantía constitucional de los entes locales, J. García Morillo, La configuración constitucional de la autonomía local, Marcial Pons, Madrid, 1998, pp. 43-49. 
de entes locales constitucionalizados, todavía no parece claro si el interés local que reconoce el artículo 137 CE quiere satisfacerse por la vía de la delegación, que sólo cede el ejercicio de las competencias, o por la vía de la atribución legislativa, que transfiere la titularidad ${ }^{14}$.

Si nos centramos en el último problema, que se refiere a la elección de las técnicas de relación intergubernamental — cesión de la titularidad o sólo del ejercicio-, todavía no se ha decidido si lo que se prefiere es un proceso de descentralización articulado por el legislador estatal y autonómico, y dirigido a incrementar la titularidad de las competencias que delimitan la autonomía local bajo el amparo de la garantía institucional de autonomía local, o, si por el contrario, se pretende un proceso organizador del ejercicio de las competencias a través de la delegación y, por ello, más dirigido al cumplimiento del principio de eficacia que a la satisfacción del interés respectivo que la Constitución reconoce en el artículo 137. Adviértase que tanto en uno como en otro caso los problemas no son menores.

En el primer supuesto, nos enfrentamos al hecho cierto de que el fundamento constitucional de la autonomía local, la teoría de la garantía institucional, que el Tribunal Constitucional ha hecho suya, ha sido matizada cuando no discutida por diversos autores debido a que presenta alguna insuficiencia para fundamentar el mayor acervo competencial de los entes locales; incluso como consecuencia de una interpretación debilitada de la reserva de ley se ha defendido una cierta autodeterminación normativa de los entes locales ${ }^{15}$.

14 Cfr. L.VAndelli, El Poder Local: Su origen en la Francia revolucionaria y su futuro en la Europa de las regiones, MAP, Madrid, 1992, pp. 23 ss., L. OrTEGA, «La Carta Europea de la Autonomía Local y el ordenamiento local español», REALA, 259, pp. 11 ss., MAP, El Pacto Local. Medidas para el desarrollo del Gobierno Local, cit., pp. 21-26.

15 El profesor García Morillo, siguiendo el camino abierto por otros autores, ha defendido, en los términos arriba expresados, la sustitución de ese fundamento de la garantía institucional por una garantía constitucional. Véanse sobre la autonomía local, M. SÁnchEz Morón, La Autonomía local: antecedentes históricos y significado constitucional, $1^{\mathrm{a}}$. ed., 1990; La autonomía local en Europa: aplicación de la Carta. 1993; J.L. RiVERo YsERn, Manual de Derecho Local, IAAP, Sevi1la, 1989, pp. 135-139, I. CAlero Fuentes, Autonomía local e institucional; G. Alarcón García, Autonomía municipal, autonomía financiera, 1ª . ed., 1995; A. CAlonge VelázQuez, Autonomías y municipios, 1995; J.M. Rodríguez Álvarez, La Carta Europea de la Autonomía Local, su significación, cit., 1996; L. SCURTo, Decentramento e autonomie locali, 1992; J. LóPEZ-MEDEL BÁsConES, Entidades locales y descentralización en un Estado autonómico, 1994; L. PAREJo Alfonso, Garantía institucional y Autonomías locales, 1981; y La potestad normativa local, 1ª ed., 1998; L. Morell Ocaña, La delegación entre entes públicos, en el derecho español, 1972; P. GómeZ Aguerre, Administración territorial y gobierno local, 1969; T. FONT I LlOVET, Informe sobre el Gobierno Local, $1^{\mathrm{a}}$ ed., Marcial Pons, Barcelona, 1992, pp. 13 y ss., L. GARcía HernándeZ, El pacto local: medidas para el desarrollo del gobierno local, $1^{\mathrm{a}}$ ed., 1999; L. ORTEGA, El régimen constitucional de las competencias locales, 1988; J. FERNÁNDEZ GARRIDO, Análisis y competencias 
En el segundo caso, también advertimos que cabe la posible utilización interesada de los entes locales por los entes autonómicos a través de la delegación o la encomienda de gestión, con instrucciones y métodos de control, y la finalidad más bien de favorecer los objetivos de las Comunidades Autónomas, con posible desprecio de la autonomía local, tradicionalmente desterrada por los legisladores estatal y autonómico al olvido de la indefinición competencial y de la insuficiencia financiera.

Debe decidirse, por consiguiente, qué caminos, técnicas y fundamentos debe adoptar el Pacto Local, esto es, qué métodos de relación intergubernamental deben adoptarse, porque de lo contrario puede ocurrir como la propuesta de Pacto Local Andaluz, presentada en abril de 1999 por la Junta de Andalucía, que mezcla la delegación de facultades con la atribución de la titularidad de las competencias, en un totum revolutum de disposiciones y buenas intenciones, donde no se discriminan los distintos fundamentos constitucionales y los principios legitimadores.

Parecida crítica debemos realizar al pretendido Pacto Local estatal, que obvió estas cuestiones como si no existieran, ignorando que su resolución constituye un prius que se antepone a la propia aprobación del Pacto Local. En este sentido, parece imprudente acometer una reforma de la esfera municipal y provincial, como también parece aventurado iniciar la ordenación territorial de Andalucía, sin la previa respuesta de por qué se realiza el Pacto Local, cuáles son sus fundamentos, bajo qué criterios se va a organizar y hacia dónde se dirige; de todo ello dependerá que se elija la delegación y la encomienda de gestión, o bien la atribución legislativa, que son títulos jurídicos diferentes cuyas consecuencias son radicalmente distintas.

En efecto, no es lo mismo que se puedan imponer directrices, como sucede en las distintas variantes de delegaciones y encomiendas, o que no se admitan, como ocurre con la atribución legislativa. Tampoco es igual que se cedan o no instalaciones y funcionarios, que quepa o no el recurso de alzada ante la Administración delegante, o la revisión de oficio frente a los actos de la Administración delegada, posibilidades todas ellas que están excluidas en el caso de la atribución legislativa de la titularidad. El mero cumplimiento del principio de seguridad jurídica, que proclama el artículo 9.3 CE, exige el cumplimiento de aquella operación,

de las corporaciones locales en materia, cit., 1987; M. ArenILla, Modernización de la Administración, cit., pp. 183 ss.; J. García Morillo, La configuración constitucional de la autonomía local, cit., pp. 37-43, y 46-49. J. GARCía RoCA, «El concepto de autonomía local según el bloque de la constitucionalidad», REALA, 282, 2000, pp. 23-70. 
REAL-2002, núm. 290. FERNÁNDEZ ALLES, JOSÉ JOAQUÍN. LOS PACTOS LOCALES, ENTRE EL...

REAL 290 (SEPTIEMBRE-DICIEMBRE, 2002)

que es previa al esclarecimiento de las técnicas que van a emplearse en cada caso.

Sólo el actual desorden metodológico, aunque también el olvido del espíritu de consenso que alumbró la Constitución de 1978, puede explicar el fracaso del Pacto Local de ámbito estatal intentado en 1998. Significativamente, el proceso de gestación del Pacto Local surgió obviando aquellas dificultades a través de un itinerario demostrativo de cuanto estamos explicando, iniciado en las Bases para el Pacto Local, documento de la Comisión Ejecutiva de la Federación Española de Municipios y Provincias (FEMP) de 24 de septiembre de 1996, continuado en la Propuesta del Gobierno sobre el Pacto Local, de 21 de julio de 1997 y en las «Bases para la negociación del Acuerdo para el Desarrollo del Pacto Local de 29 de julio de 1997», suscrito en el seno de la FEMP (por la comisión ejecutiva de la FEMP en su reunión del día 24 de septiembre de 1996), y plasmado en el citado conjunto de nueve proyectos de ley, de «acompañamiento» del frustrado Pacto Local, que, como vimos, terminaron por ser seis leyes ${ }^{16} \mathrm{y}$

16 Según dijo en su momento el Ministro Rajoy, el Pacto Local suponía la reforma de nueve leyes muy importante, pero no citaba cuáles. ABC, 26-4-1998, p. 16, y El País, 26-4-1998, p. 1. Luego se supo que el proyecto que se pensaba presentar en la Cortes recogía cambios legislativos en los siguientes textos: a) LRBRL 7/85, 2-8, LRHL 39/88, 28-12, LRJAP y PAC 30/92, 26-11, LOFAGE 6/97, 14-4, y LOTC 2/79, 2-10. Finalmente, el Pacto Local sobre la reforma del régimen local español ha quedado reducido y circunscrito a la firma de un acuerdo en el Ministerio de Administraciones Públicas sobre figura de los tránsfugas, a la ampliación de legitimación para acudir al Tribunal Constitucional y a los instrumentos de control del Pleno de los Ayuntamientos, aspectos estos dos últimos que, como vimos, se encuentran en fase de tramitación parlamentaria. El Acuerdo del Consejo de Ministros contenía un paquete de reformas de cinco leyes orgánicas y una ordinaria, para su presentación como proyectos de leyes en el Congreso para su posterior tramitación parlamentaria para el período de sesiones correspondiente a otoño de 1998. En consecuencia, lo que inicialmente se concibió como nueve reformas legislativas, se convirtió en un conjunto de iniciativas legislativas que se tradujo, primero, en la reforma de seis leyes cuyos textos fueron aprobados en el Consejo de Ministros por Acuerdo de 17 de junio de 1998, y después, ya en las Cortes Generales, en cinco procedimientos legislativos relativos a la LO 7/85, de 2-4, Reguladora de las Bases de Régimen Local y otras medidas para el desarrollo del Gobierno Local, en materia de tráfico, circulación de vehículos de motor y seguridad vial, y en materia de aguas, a la LO 5/85, de 19-6, del Régimen Electoral General y a la LO 2/1979, de 3-10, del Tribunal Constitucional, a la LO 8/1985, de 3-7, Reguladora del Derecho a la Educación, y a la LO 1/1992, de 21-2, sobre protección de la seguridad Ciudadana. A todo ello se ha unido el RD 1259/1999, de 16-7, por el que se regulan las cartas de servicios y los premios a la calidad en la Administración General del Estado. BOE 190, 10-8-1999, pp. 29.460 ss. En cuanto a los precedentes en la documentación parlamentaria, véase también Moción del Grupo Parlamentario Federal de Izquierda Unida-Iniciativa per Catalunya, sobre la política del Gobierno respecto de las administraciones locales y en concreto la referida al conocido como «Pacto Local». Se propugna un pacto local que sitúe a los municipios con un mayor protagonismo en un modelo de Estado diferente y que profundice en la realidad que emanaba de la Constitución de 1978. Basa la defensa de su moción en los mismos criterios que expuso en la interpelación de la semana pasada, cuyo principal objetivo era resaltar ante el Gobierno y ante las fuerzas políticas la necesidad de un debate y una reflexión sobre los municipios, y añade que disponen de un estudio detallado de las competencias municipales y del 
que, con carácter auxiliar, venían a allanar el camino a la reforma en el ámbito local ${ }^{17}$. Seis leyes que, sin duda, hubieran conducido a un verdadero hito en el devenir de las estructuras territoriales y administrativas españolas, si hubieran ido acompañadas, lo que no ha ocurrido, por el citado Pacto Local. Sin éste, las seis leyes deben relacionarse con las siguientes cuatro medidas gubernamentales: 1) el Acuerdo de 7 de julio de 1998 sobre el Código de buena conducta en relación con el transfuguismo en las corporaciones locales, que suscribieron todos los partidos con representación parlamentaria, 2) el Acuerdo del Consejo de Ministros de 17 de julio de 1998, de medidas de carácter administrativo para dar respuesta a las demandas de los entes locales integrados en el ámbito competencia del Estado, 3) los acuerdos suscritos con la Federación Española de Municipios y Provincias sobre medidas a adoptar en relación con la financiación de las corporaciones locales durante el quinquenio 1999-2003, incluidas las oportunas modificaciones de la Ley 39/88, de 28-12, Reguladora de las Haciendas Locales ${ }^{18}$ y 4) el RD 1259/1999, de 16-7, por el que se regulan, en cumplimiento del artículo 4 de la LOFAGE 6/96, las cartas de servicios y los premios a la calidad en la Administración General del Estado.

Mientras no se resuelvan los problemas previos y se acuerden los pactos locales, las leyes de 21 de abril de 1999 quedan relegadas a la consideración de medidas legislativas dirigidas a integrar lagunas jurídicas, incorporar la doctrina de la jurisprudencia constitucional y regular, obligados por la experiencia de los últimos años, mecanismos de participación y control en el funcionamiento de los entes locales que hacía tiempo debían haber tenido adecuada respuesta normativa. Un conjunto de leyes que debe esperar, insistimos, la determinación de las relaciones intergubernamentales que se quieren elegir, la concreción del ámbito material del Pacto Local y, sobre todo, su conexión con el fundamento constitucional de la autonomía local ${ }^{19}$.

pacto local, realizado por el Ministerio de Administraciones Públicas, entrando a analizar área por área las competencias que habían sido solicitadas por la propia Federación de Municipios y Provincias. Añade que este trabajo se ve reforzado con la declaración solemne en el debate de investidura sobre la necesidad y el compromiso de un pacto local, compromiso que ha quedado tan sólo en unas medidas de competencias en el suelo y en una reducción del poder municipal. Diario de Sesiones del Congreso de los Diputados, Año 1996 VI Legislatura, núm. 16, pp. 668 ss.

${ }^{17}$ Según dijo en el debate de totalidad el entonces Ministro de Administraciones Públicas, Mariano Rajoy, este conjunto de proyectos constituye el paquete normativo de mayor trascendencia para las entidades locales desde su aprobación, hace ya trece años, de la LRBRL. Cfr. Diario de Sesiones del Congreso de los Diputados, 200, 16-11-1998, pp. 10.751-10.752. Las leyes, en el BOE, 224-1999, núm. 96, pp. 14.922-14.936.

18 Cfr. Diario de Sesiones del Congreso de los Diputados, 200, 16-11-1998, p. 10.753. MAP, El Pacto Local. Medidas para el desarrollo del Gobierno Local, cit., pp. 185-186.

19 Cfr. E. AJA, «Propuestas...», cit., pp. 152-154. También en Informe sobre Comunidades Autó- 


\section{EL PACTO LOCAL ANDALUZ}

En el ámbito de Andalucía, la génesis del Pacto Local autonómico se remonta ocho años atrás, cuando los entes locales andaluces acordaron en la IV Asamblea de la Federación Andaluza de Municipios y Provincias (FAMP), celebrada en Sevilla los días 24 y 25 de noviembre de 1995, avanzar en el proceso de descentralización, justo los mismos términos adoptados en la reunión de 13 y 14 de noviembre de 1999.

Acogida con interés desde un primer momento, tanto por la Junta de Andalucía, como por los partidos políticos, esta iniciativa ha pretendido reforzar la autonomía local a través de un incremento de las competencias administrativas de Ayuntamientos y Diputaciones Provinciales, con la consiguiente disminución de la función ejecutiva autonómica. Tras una primera fase de estudio y valoración de las demandas iniciales de los municipios y de las propuestas de las distintas formaciones políticas, no siempre coincidentes en el contenido y en los fines, se elaboró conjuntamente con la FAMP un primer documento de trabajo en el que se preveía la constitución de una Mesa del Pacto Local Andaluz y de Mesas Sectoriales para los distintos sectores competenciales, del que resultó un proyecto de desarrollo del Pacto Local Andaluz, vertebrado en diversas fases que debían atender a la complejidad de las materias y al grado de acuerdo sobre la descentralización.

En el seno de los entes locales, este proceso complejo y de pretendidas consecuencias constitucionales, al redefinir el contenido efectivo de la autonomía local, ha encontrado una acogida favorable aunque siempre bajo la sombra del escepticismo fundado, y de una duda asumida por todos, de que la instancia autonómica, con menos décadas de existencia, tenga voluntad seria de desprenderse de un poder recientemente adquirido, y no limite la reforma a la descentralización de las competencias más gravosas, menos atractivas y de peor imagen ante los ciudadanos. Sea como fuere, lo cierto es que el proceso inició su andadura, al menos, en el plano institucional cuando el Presidente de la Junta de Andalucía presidió la primera reunión ad hoc el día 4 de marzo de 1998, en la que se decidió la creación de un órgano de coordinación del proceso al más alto nivel, lo que se verificaría el día 13 de abril de 1998, con la constitución de la Mesa del Pacto Local Andaluz.

La Mesa del Pacto Local Andaluz, configurada como el órgano encargado de coordinar, supervisar e impulsar los trabajos de las distintas fases de negociación, quedó integrada, en representación de la FAMP, por su Presidente, los cuatro Vicepresidentes, y el Secretario General; y, en repre- 
sentación de la Junta de Andalucía, por los Consejeros de Presidencia, de Gobernación, y de Justicia y Administración Pública (antes Gobernación y Justicia), de Economía y Hacienda, el Viceconsejero de Gobernación (antes Gobernación y Justicia) y el Director General de Administración Local.

En cumplimiento de los Acuerdos adoptados por la Mesa del Pacto Local Andaluz, durante el segundo semestre de 1998 quedaron constituidas las Mesas Sectoriales siguientes: Asuntos Sociales (23 de julio 1998); Trabajo e Industria (29 de julio de 1998); Obras Públicas y Transportes (31 de julio de 1998); Medio Ambiente (25 de septiembre de 1998); Turismo y Deportes (25 de noviembre de 1998); Educación y Cultura (10 de diciembre de 1998); Presidencia, Gobernación y Justicia (14 de diciembre de 1998); Salud, Trabajo e Industria (18 de diciembre de 1998). Estas Mesas están integradas, por parte de la Junta de Andalucía, por representantes con rango de Director General, de las Consejerías de Gobernación, de Justicia y Administración Pública, y de Economía y Hacienda, así como de las Consejerías afectadas en cada caso; y, por parte de la FAMP, por miembros de las Comisiones de Trabajo que correspondan y un representante de su Secretaría General.

Posteriormente, diversas normas se han erigido en herederas del non nato Pacto Local Andaluz, invocando sus fundamentos y articulando diversas técnicas de apariencia descentralizadora, como en el caso de la Ley 7/2002, de 17 de diciembre, de Ordenación urbanística de Andalucía, cuya Exposición de Motivos se propone avanzar en la asignación de competencias en materia de urbanismo a los municipios andaluces, como hiciera el Decreto 77/1994, de 5 de abril, de delegación de competencias en materia de urbanismo a los municipios. A este proceso se han sumado diversas propuestas parlamentarias alternativas a la del Gobierno autonómico, entre las que destaca la proposición de ley para el desarrollo de la descentralización autonómica a favor de las entidades locales de Andalu-

nomas 1987, cit. La Ley 11/1999, de 21-4, de modificación de la Ley 7/85, de 2-4, Reguladora de las Bases de Régimen Local y otras medidas para el desarrollo del Gobierno Local, en materia de tráfico, circulación de vehículos de motor y seguridad vial; en materia de aguas, que reforma el artículo 58 de la LRBRL, prevé que la legislación sectorial regule la participación de los municipios en la formación de los planes generales de obras públicas que les afecten, y el artículo 17 de la Ley 29/1985, de 2-8, de Aguas, que prevé la representación de los entes locales en el Consejo Nacional del Agua, un órgano consultivo donde también están representados el Estado y las Comunidades Autónomas. En la misma línea, la Ley 10/1999, de 21-4, de modificación de la Ley Orgánica 8/1985, de 3-7, Reguladora del Derecho a la Educación, prevé la participación de los entes locales en el Consejo Escolar del Estado, a través de las asociaciones de ámbito estatal con mayor implantación. Cfr. BOE, 96, 1999, cit, pp. 14927, 14935 y 14936. 
cía presentada por el Partido Popular el 18 de diciembre de 2002, rechazada por el Pleno ${ }^{20}$.

Ahora bien, debe advertirse que la creación de la Mesa, a raíz de la cual surgió, en abril de 1999, la propuesta de Pacto Local Andaluz, como elemento necesario para negociar y decidir el acuerdo definitivo, representa «un empezar la casa por el tejado», en parte por las razones metodológicas que exponíamos más arriba; previamente, deberán resolverse diversos problemas financieros y cuestiones de gran trascendencia relativas a la ordenación del territorio y a las técnicas de aplicación del pacto local y a su naturaleza jurídica.

\section{CÓMO PASAR DE LA RETÓRICA POLÍTICA AL DERECHO EN EL DEBATE SOBRE LOS PACTOS LOCALES: UNAS PRECISIONES CONCEPTUALES}

El uso y, en ocasiones, el abuso de la expresión Pacto Local, con frecuencia empleadas con laxitud y falta de rigor, nos llevan a realizar unas precisiones conceptuales sobre la denominada segunda descentralización, y sobre las relaciones intergubernamentales entre el poder autonómico y los poderes locales, como base imprescindible para que del exceso de retórica sobre los pactos locales, vivido en los últimos años, pueda evolucionarse hacia su aplicación a la práctica legal y administrativa.

a) Sabemos que la autonomía local, reconocida en el artículo $137 \mathrm{CE}$ y fundamentada en una garantía institucional, que es obra de la doctrina jurídica y de la jurisprudencia constitucional, encuentra asimismo su amparo en la citada Carta Europea de Autonomía Local de 15 de octubre de 1982, ratificada por España por Instrumento de 20 de enero de 1988, que reconoce el principio de subsidiariedad. Pues bien, si este principio depende de varios criterios, principalmente la cercanía al ciudadano, la eficacia de la acción y la capacidad o suficiencia de los entes locales para gestionar las competencias, lo cierto es que este último criterio a su vez está supeditado a los recursos económicos de que disponen los entes locales, que como

\footnotetext{
${ }^{20}$ Véanse la Proposición de Ley para el desarrollo de la descentralización autonómica a favor de las entidades locales de Andalucía. Boletín Oficial del Parlamento de Andalucía, 437, de 7 de enero de 2003, pp. 1 a 10, y Partido Popular. Manifiesto por la Segunda Descentralización, Los Ayuntamientos de Andalucía con más competencias y con más recursos. 25 de enero de 2003. Su marco legislativo, en A.J. Porras Nadales, Legislación de la Comunidad Autónoma de Andalucía, $3^{\text {a }}$ ed., 2 vols., Sevilla, 2000; A.J. Porras Nadales y J.J. Ruiz-Rico (eds.): El Estatuto de Autonomía de Andalucía, Barcelona, Ariel, 1990; J.L. García Ruiz, El Derecho propio de Andalucía, Jerez, Fundación Universitaria, 1992, pp. 23-35.
} 
hemos visto, han sido muy limitados por las vigentes leyes estatales y autonómicas. En consecuencia, el problema financiero no es un problema más del Pacto Local sino un elemento definitorio de su capacidad ${ }^{21}$.

b) El principio de subsidiariedad no constituye un criterio de reparto competencial, ni tampoco de fundamentación constitucional de la autonomía local. Son los artículos 137 a 142 CE los preceptos que prevén los dos principios básicos configuradores del sistema local: la autonomía y la suficiencia financiera de las Corporaciones Locales, pensados para permitir una amplia transformación de la estructura local. Y ello con independencia de que la Ley 7/1985, que regula con carácter básico los ámbitos materiales de la autonomía local, pueda necesitar un proceso revisionista, como propugnan algunos profesores. Hasta ahora, la garantía institucional ha fundamentado, generalmente con solvencia, la autonomía local reconocida en el artículo $137 \mathrm{CE}$, concretándose en la atribución de ámbitos competenciales materiales y funcionales por la legislación básica estatal, por la legislación estatal y autonómica de régimen local, así como por la legislación sectorial estatal y autonómica. Sin embargo, las lagunas de esta garantía institucional a la hora de proteger adecuadamente, en algunos ámbitos, el derecho constitucional de los entes locales, pueden llevarnos a nueva construcción de la garantía constitucional de la autonomía local, fundamentada en un método de razonabilidad y en el criterio entre la dimensión del municipio y su capacidad de gestión ${ }^{22}$.

c) Tanto el Pacto Local de ámbito estatal como los distintos pactos locales de ámbito autonómico, en particular el de Andalucía, necesitan esclarecer y decidir previamente, y en cada caso, cuáles son las técnicas que van a adoptar para que los entes locales ejerciten más competencias administrativas. Una cuestión sin duda importante porque no es lo mismo delegar la gestión de una función administrativa, que atribuir por ley sectorial la titularidad de la misma. Todo lo flexible y dinámica que resulta la delegación se torna, por el contrario, en rigidez en el caso de la ley, que sin embargo se muestra más respetuosa con la autonomía local. Si la ley define el ámbito del interés respectivo propio del ente local, por su parte, la delegación sólo es un instrumento para que la Administración estatal, y

${ }^{21}$ Cfr. T. Font i Llovet, «Administración Local y Comunidades Autónomas», L. M. Rebollo (dir.), El futuro de las Autonomía Territoriales. Comunidades Autónomas: Balance y perspectivas, Servicio de Publicaciones de la Universidad de Cantabria. Asamblea Regional de Cantabria, 1991, pp. 172 ss.

22 Cfr. E. AJA, «Configuración constitucional de la autonomía local», Informe sobre el Gobierno Local. MAP, Madrid, 1992; sobre la construcción directa de una reserva constitucional, J. GARCíA MoRILlo, La configuración constitucional de la autonomía local, cit., pp. 77 ss. 
sobre todo, la autonómica se sirvan del ente local para gestionar competencias cuya titularidad siguen conservando; al elegir la delegación o la encomienda de gestión, el núcleo esencial de la autonomía constitucionalmente reconocida queda relegada a un segundo plano.

Ni la propuesta de Pacto Local para España, ni el que se propugna por la Junta de Andalucía, parecen haber tenido claro estos problemas. Así, la propuesta de Pacto Local Andaluz, de abril de 1999, mezcla atribución legislativa y delegación en un mismo apartado de medidas, y bajo el título «Normativa sectorial vigente por la que se atribuyen competencias a las Corporaciones Locales» engloba, por ejemplo, las técnicas de delegación reguladas en los artículos 18 y 19 de la Ley 2/1988, de 4 de abril, de Servicios Sociales, o en el artículo 22 del Decreto 77/1994, de 5 de abril, por el que se regula el ejercicio de competencias de la Junta de Andalucía en materia de Ordenación del Territorio y Urbanismo. Una mixtificación de técnicas y fundamentos que no acaba ahí, pues a la atribución legislativa y la delegación se unen, como variantes de un mismo fenómeno, la participación orgánica de los entes locales en las instituciones autonómicas o los instrumentos de coordinación y cooperación ${ }^{23}$.

A nuestro entender, los criterios de flexibilidad y de razonabilidad deben presidir siempre el proceso de articulación de las técnicas de aplicación del Pacto Local, en atención a la materia de que se trate. Aquellos ámbitos donde la gestión pública y la dimensión de la acción administrativa sean más dinámicas y estén sujetas a más cambios organizativos, deberán ser objeto de delegación o encomienda de gestión. Por el contrario, aquellos otros ámbitos firmemente incardinados, conforme a criterios económicos y técnicos, en una estructura organizativa propia de la dimensión local, deberán atribuirse por ley a los municipios o, en su caso, a las provincias, cuya autonomía ha de quedar configurada por estas leyes de atribución, a través de métodos de razonabilidad propios de la Ciencias de la Administración, el marketing público, o la teoría de la organización. Resulta fundamental asimismo que, siguiendo el principio de motivación de los actos y normas, que es condición de seguridad jurídica, queden claras en cada momento las razones que han llevado a elegir una u otra técnica. Sólo esta fundamentación posibilitará el ejercicio de los controles previstos por el ordenamiento y la salvaguarda, sin discriminación posible entre los distintos entes locales, de la autonomía local.

23 Pacto Local Andaluz. Propuestas para su desarrollo. Junta de Andalucía, Consejería de Gobernación y Justicia. Dirección General de Administración Local, abril, Sevilla, 1999, pp. 6-10. 


\section{EL PACTO LOCAL COMO MÉTODO PARA LAS RELACIONES INTERGUBERNAMENTALES ENTRE LA COMUNIDAD AUTÓNOMA Y LOS ENTES LOCALES}

La teoría constitucional española sobre relaciones intergubernamentales, definida como construcción sistemática de los instrumentos de cooperación ejecutiva entre los gobiernos de los entes territoriales, nos ofrece las siguientes técnicas para cumplir los deberes de colaboración y coordinación proclamados por la jurisprudencia constitucional:

$\left.1^{\circ}\right)$ La atribución legislativa de competencias.- Son competencias atribuidas aquellas respecto de las cuales los entes locales detentan la titularidad y el ejercicio por reconocimiento de la ley estatal o autonómica (arts. 25.2 y 36.1 Ley básica 7/1985). Los entes locales reciben no sólo el ejercicio sino también la titularidad de las competencias cuando, en desarrollo del artículo $137 \mathrm{CE}$ y de los ámbitos materiales señalados por la Ley básica 7/1985, así lo disponen las legislaciones estatal (incluida la legislación básica citada) y la autonómica, sobre todo la de carácter sectorial. Según el artículo 5.1 Ley 12/1984, del Proceso Autonómico: «Sin perjuicio de las competencias que la legislación de régimen local, tanto del Estado como de las Comunidades Autónomas, atribuya a las Diputaciones Provinciales, las Leyes de las Comunidades Autónomas podrán transferirles competencias propias a la Comunidad o delegarles su ejercicio, siempre bajo la dirección y control de éstas». En este caso, las Diputaciones Provinciales podrán asumir la gestión ordinaria de los servicios propios de la Administración Autonómica en el territorio de la provincia, en los términos que los Estatutos y dichas Leyes establezcan. La limitación legal se establece en el último inciso del artículo 5.1 Ley 12/1984, 14-10, según el cual, las transferencias o delegaciones se efectuarán siempre para la totalidad de las Diputaciones Provinciales comprendidas en el ámbito territorial de la respectiva Comunidad Autónoma.

$2^{\circ}$ ) La delegación legislativa obligatoria (artículo 27.3 Ley básica 7/1985).

$3^{\circ}$ ) La delegación (arts. 27 y 37 de la Ley básica 7/1985, y los arts. 5 y 8 de la Ley 12/1983, del Proceso Autonómico) o la encomienda de gestión de facultades administrativas (artículo 15 de la Ley 30/1992).

$\left.4^{\circ}\right)$ Otros mecanismos de Administración indirecta, mediante la utilización de los aparatos locales por las Comunidades Autónomas, que, más allá del nomen iuris, vienen a ser subtipos de la delegación o la encomienda de gestión, como ocurre con la asignación de competencias en 
Andalucía (artículo 21 de la Ley andaluza 3/1983, de 1 de junio, de Organización Territorial de la CA de Andalucía).

$\left.5^{\circ}\right)$ La coordinación general de las competencias locales desde las Comunidades Autónomas.

$\left.6^{\circ}\right)$ El convenio de colaboración, con carácter exclusivo o complementario, incluidos los reguladores de los consorcios, así como los planes y programas conjuntos (arts. 5 a 8 de la Ley 30/1992).

De todas estas técnicas debe destacarse, en primer lugar, la encomienda de gestión del artículo 15 de la Ley 30/1992; en segundo lugar, el artículo 8.1 de la Ley 12/1983, que prevé una delegación legislativa a tres bandas o de segundo grado: «Las Comunidades Autónomas podrán delegar en las Diputaciones Provinciales, según la naturaleza de la materia, el ejercicio de competencias transferidas o delegadas por el Estado a aquéllas, salvo que la Ley a que se refiera el artículo 150.2, de la Constitución, disponga lo contrario», con la limitación de su párrafo 2, según el cual, el Estado no podrá transferir o delegar directamente sus competencias a las Diputaciones Provinciales, pero podrá encomendar a éstas el servicio de recaudación de tributos. Y, en tercer lugar, el artículo 27 Ley básica $7 / 1985$, donde se regula la delegación obligatoria y por ley ordinaria de competencias en los entes locales.

En los demás casos, la cesión de facultades a las Corporaciones Locales podrá articularse, bien a través de la delegación regulada en los artículos 27 (municipios) y 37 (provincias) de la Ley 7/1985, que no precisa ley y que es voluntaria para los entes locales, que pueden o no aceptarla (artículo 27.3); bien por la atribución de una ley estatal (incluida la reforma de la Ley 7/1985), cuando se trate de facultades estatales; o bien, en último lugar, por ley autonómica sectorial, en los casos así permitidos a las Comunidades Autónomas por el bloque de la constitucionalidad y por la Ley básica 7/1985. En el supuesto de la delegación voluntaria a los municipios, el artículo 27.1 Ley básica dispone: «La Administración del Estado, de las Comunidades Autónomas y otras entidades locales podrán delegar en los Municipios el ejercicio de competencias en materias que afecten a sus intereses propios, siempre que con ello se mejore la eficacia de la gestión pública y se alcance una mayor participación ciudadana». Por su parte, el artículo 37.1 relativo a las provincias amplía las técnicas aplicables a la encomienda de gestión por las Comunidades Autónomas, ya que éstas, en virtud del precepto citado, «podrán delegar competencias en las Diputaciones, así como encomendar a éstas la gestión ordinaria de servicios propios en los términos previstos en los Estatutos correspondientes», disponiéndo- 
se por su parte en el artículo 37.2 que «[e]l Estado podrá, asimismo, previa consulta e informe de la Comunidad Autónoma interesada delegar en las Diputaciones competencias de mera ejecución cuando el ámbito provincial sea el más idóneo para la prestación de los correspondientes servicios».

En el caso de Andalucía, mención especial merece, como dijimos, la asignación de competencias, una técnica formalmente sin estrenar, pero prevista por el artículo 21 de la Ley 3/1983, de 1 de junio, de Organización Territorial de la Comunidad Autónoma de Andalucía, que constituye una «encomienda de gestión controlada o reforzada» en las Diputaciones Provinciales, al permitir al ente delegante, en este caso la Administración andaluza, la posibilidad de conservar poderes de dirección y organización y que, por eso mismo, invade, con todo lo que ello supone, el ámbito de autoorganización del ente delegado ${ }^{24}$. Se trata de una técnica circunscrita a las delegaciones de la Junta de Andalucía en las Diputaciones Provinciales, que completa su regulación, con más de un problema de técnica legislativa, en la Ley 11/1987, de 26 de diciembre, Reguladora de las Relaciones entre la Comunidad Autónoma y las Diputaciones Provinciales; ley que omitió toda referencia a la gestión ordinaria de los servicios autonómicos por las Diputaciones, llevando a cabo una atribución de competencias a favor de éstas en una serie de materias (cultura, deporte y turismo) y delegando el ejercicio de otras como servicios sociales y carreteras ${ }^{25}$.

\footnotetext{
${ }^{24}$ Según el artículo 21.1 de la citada Ley 3/1983, son competencias asignadas las que comporten ejecución de la gestión ordinaria de los servicios periféricos y que con tal carácter se asuman por las Diputaciones Provinciales siempre que el ámbito de aquéllas coincida con el de éstas. La Comunidad Autónoma articulará sus servicios periféricos a través de las Diputaciones cuando su naturaleza permita la gestión ordinaria de aquéllos, a través de éstas. Se sujeta así la asignación a un criterio jurídico indeterminado pero de carácter técnico: «la naturaleza de los servicios». El acuerdo que asigne la gestión ordinaria de servicios periféricos se adoptará por el Consejo de Gobierno y deberá concretar las facultades de dirección y control que la Comunidad Autónoma se reservan y, sin ánimo exhaustivo, podrán ser: a) En todo caso, la potestad reglamentaria sobre la materia y sobre la organización del servicio; b) El establecimiento de recursos de alzada y la facultad de promover la revisión de oficio; c) La designación de Director o Directores de servicios; d) La fijación de Módulos de funcionamiento y financiación de niveles de rendimiento mínimo; y e) Elaborar programas y dictar directrices sobre la gestión de las competencias, recabar, en cualquier momento, información sobre la gestión, enviar comisionados y formular los requerimientos pertinentes al Presidente del ente, para la subsanación de las deficiencias observadas. Cfr. J.L. Rivero Ysern, Manual de Derecho Local, cit., pp. 137-139; J. I. Morillo-Velarde, «Notas sobre la Ley de 26 de diciembre de 1987 reguladora de las relaciones entre la Comunidad Autónoma de Andalucía y las Diputaciones Provinciales de su territorio», ibidem.
}

25 Cfr J.I Morillo-Velarde, «Los Delegados del Gobierno de la Junta de Andalucía», cit., pp. 345-347; J. L. Rivero IsERn, Manual de Derecho Local, cit., pp. 133-136. 


\section{REFLEXIONES CONCLUSIVAS}

1) El protagonismo de la institución autonómica ha ensombrecido a la institución local, que ha estado relegada durante años, y si durante un tiempo hubo excusa para explicar este desfase, puesto que desde el punto de vista jurídico no era posible resolver adecuadamente importantes puntos de la reforma local sin haber definido antes la posición de las Comunidades Autónomas dentro del conjunto de la organización territorial, desde 1992, fecha del último gran pacto autonómico, esta explicación ha dejado de tener justificación. Ha llegado, por tanto, la hora de afrontar la regulación de los entes locales bajo el principio de servicio al ciudadano, de la eficacia, de la eficiencia y de la calidad en la prestación; sobre todo, porque al fundamento constitucional le asisten el principio de subsidiariedad y la Carta Europea de Autonomía Local, que abogan por una descentralización en la esfera local de materias concurrentes y porque determinados servicios se presten por el ente que más cerca esté del ciudadano. Después de diez años de debate sobre los Pactos Locales, la retórica política ha de dejar paso al Derecho.

2) El Pacto Local, como técnica de las relación intergubernamental, no se articula entre Administraciones Públicas sino entre el Consejo de Gobierno y los gobiernos locales, precisándose en algunos casos la intervención legislativa del Parlamento de Andalucía: ley de atribución competencial, ley de creación de áreas metropolitanas...

Lo anterior significa que no estamos ante simples relaciones interadministrativas sino relaciones de carácter intergubernamental, en el sentido acogido en la Ley 50/1997, de 27-11, del Gobierno; relaciones intergubernamentales que, en consecuencia, no son meramente interadministrativas, como se las califica mayoritariamente (incluso por el legislador, en el Título V, Capítulo II, Relaciones interadministrativas, arts. 55 a 62, de la Ley $7 / 1985$, de 2 de abril), sino de carácter intergubernamental, ya que vinculan a dos o más gobiernos, quienes al relacionarse ejercitan su potestad de dirección política (indirizzo político, Staatsleitung). Quizás el punto clave de diferenciación reside en el hecho de que no se puede confundir el objeto de la teoría constitucional sobre relaciones intergubernamentales, de naturaleza jurídico-política, con el objeto de sus técnicas, de naturaleza jurídico-administrativa: las facultades administrativas.

3) El Pacto Local emplea como técnicas preferentes para su puesta en práctica, bien la atribución legislativa de la titularidad de las competencias, bien la cesión del ejercicio (la delegación y la encomienda de gestión en los entes locales de facultades administrativas autonómicas), pero también 
instrumentos normativos y orgánicos de cooperación, como el convenio y los consorcios. En cualquier caso, se trata de dos grupos de técnicas cualitativamente diferentes - la transferencia de la titularidad (atribución legislativa) frente a la delegación o encomienda del ejercicio de la competencia— que no pueden ser confundidas ni mezcladas porque responden a fundamentos y regímenes distintos. No es lo mismo que se puedan o no imponer directrices, que se cedan o no instalaciones y funcionarios, que quepa o no el recurso de alzada o la revisión de oficio frente a los actos de la Administración delegada. La elección en cada caso de una u otra dependerá de la materia y de la dimensión, de la eficacia de la acción y de la capacidad del municipio. Tampoco se pueden confundir las técnicas de cooperación ejecutiva - la delegación: para que otra Administración ejecute la competencia - con las técnicas de cooperación consorcial. Si las primeras se dirigen a que una «Administración única» gestione las competencias concurrentes de dos niveles de gobierno, las segundas establecen procedimientos conjuntos de gestión competencial.

Ejemplos de cooperación ejecutiva través de transferencia, en el nivel de relaciones Estado-Junta de Andalucía, son las trescientas dos oficinas únicas de empleo, reguladas por la Ley 4/2002, de 16 de diciembre, de Creación del Servicio Andaluz de Empleo, suma de las ciento doce unidades territoriales más las ciento noventa transferidas el 1 de mayo de 2003, que asumen con carácter de servicio local las competencias transferidas por Real Decreto 467/2003, de 25 de abril, sobre traspaso a la Comunidad Autónoma de Andalucía de la gestión realizada por el Instituto Nacional de Empleo, en el ámbito del trabajo, el empleo y la formación. Otro supuesto, esta vez de delegación funcional, se prevé en el artículo 94 de la Ley 7/2002, de 17 de diciembre, de Ordenación Urbanística de Andalucía, sobre delegación intersubjetiva. Por su parte, un ejemplo de cooperación orgánica, en el nivel de relaciones Junta de Andalucía-Ayuntamientos, se regula en la citada Ley 7/2002, que regula los consorcios urbanísticos.

El Pacto Local consiste, en definitiva, en el modo acordado en que dos gobiernos con competencias concurrentes pueden dar mejor cumplimiento a los principios de eficacia y coordinación, eliminando las disfunciones, duplicidades y desconexiones de nuestro complejo sistema competencial, y, como ocurre con las oficinas de empleo en Andalucía, acercando el servicio al ciudadano.

4) El proceso descentralizador propugnado por el Pacto Local, en el que tendrán mucho que decir, además de los Ayuntamientos y Diputaciones Provinciales, las mancomunidades de municipios y — sobre todo a la vista de las últimas propuestas en Andalucía - las áreas metropolitanas, 
más que las comarcas o entidades menores, deberá ser llevado a cabo por el Estado y por las Comunidades Autónomas, tomando en consideración la diversidad de situaciones existentes y las distintas cargas competenciales que se prevean para cada nivel. Más que operaciones de revisión del mapa municipal se trata de reforzar las entidades ya creadas, siempre con exquisito cuidado y, en todo caso, de acuerdo con los municipios, cuyo asentimiento constante, materializado en un convenio suscrito entre las Administraciones afectadas, asegurará que no sufra su función de identificación política de las colectividades locales y que no se generen procesos centralizadores. Debe recordarse también que con la regulación actual de la Ley Orgánica 5/1985, 19 de junio, Reguladora del Régimen Electoral General y de las leyes autonómicas, un proceso de delegación exclusivo, por ejemplo en los entes mancomunados, significaría un proceso simultáneo de rebaja del nivel democrático del ejercicio de las competencias y, por consiguiente, una merma del principio de control de los poderes y de identificación elector-gobernante, ya que en estos casos el sistema de representación es indirecto, más devaluado incluso que en las Diputaciones Provinciales, sin elecciones que permitan a los ciudadanos designar a los representantes de la mancomunidad, que hoy por hoy son representantes de segundo grado.

Asimismo, deberá incrementarse la intervención y la presencia política de la Administración local en la toma de decisiones del Estado y de las Comunidades Autónomas, especialmente a través de una revalorización de las federaciones y asociaciones de municipios o de otros entes locales. En este sentido, si la actual composición y las funciones de la Comisión Nacional de Administración Local no resultan desde luego las más acertadas, ni siquiera suficientes tras las reformas de 21 de abril de 1999, que incluso le encomienda el Informe sobre los Anteproyectos de ley y proyectos de disposiciones administrativas del Estado (artículo 118.1.A a de la Ley básica 7/1985), y si la Federación Española de Municipios y Provincias, y sus equivalentes autonómicas, no cumplen esa función, sin duda deberá ser el Senado, como Cámara de representación territorial, y no exclusivamente autonómica, la sede donde tengan voz y voto los representantes de grandes conurbaciones, áreas metropolitanas, mancomunidades de municipios, provincias y municipios.

5) Finalmente, si se quiere que el Pacto Local salga del limbo en el que se encuentra hospedado desde hace una década, y su invocación no quede circunscrita a una vacua retórica sin posibilidad de realización, los partidos políticos de ámbito estatal deben convencerse de que no estamos ante un simple asunto de política local, sino, antes bien, frente a una «cuestión 
de Estado» que ha de resolverse a través de un proceso de descentralización administrativa a favor de los entes locales y de una simultánea regularización del régimen local en aspectos tan relevantes para la democracia, como la función pública, la contratación, el urbanismo o el régimen de subvenciones, en ocasiones «huidos del Derecho». 


\section{Jurisprudencia}

REAL-2002, núm. 290. FERNÁNDEZ ALLES, JOSÉ JOAQUÍN. LOS PACTOS LOCALES, ENTRE EL... 